\title{
Cloud-Based College Management Information System for Universities
}

\author{
Mary Jane Magno-Tan, Allan V. Crisostomo, Bill Villaflor, and James C. Faller
}

\begin{abstract}
Because all colleges within universities are being evaluated for funding and program accreditation primarily in terms of the college's curriculum, faculty, physical facilities, research, and extension works, it is therefore important that documents and records related to these areas be managed efficiently from the creation, storage, update, communication and dissemination. As individual colleges are managed by their respective deans and chairpersons, it is also important that relevant and accurate reports on gathered information be available to them for informed college-wide decisions and plans. This study aimed to design and develop a cloud-based customizable system that provides detailed and summarized information on these critical areas to guide college administrators in planning and decision-making. It is accessible anywhere anytime as data is stored remotely and made available to users over the internet. Object-oriented method was used in the design and development of the computerized system following an incremental development process. In developing and testing the software, an evolutionary or operational prototype was created. It is tested to the College of Computers and Information Science (CCIS) of the Polytechnic University of the Philippines (PUP). To evaluate the developed system, the study used questionnaire-checklist accomplished by the system users and information technology (IT) experts. The system was evaluated in terms of functionality, user-friendliness, usability, security, performance and robustness. Results gathered showed that evaluators rated the software very satisfactory in terms of functionality, user-friendliness, usability, performance, and security; and good in terms of robustness. This implies that other colleges may adopt this system for more efficient information management and more effective management decisions.
\end{abstract}

Index Terms-Cloud-based system, college management information system, document management system, management information system.

\section{INTRODUCTION}

Nobody can ignore the national and international contributions of higher educational institutions in terms of manpower development and knowledge creation that is why government and private organizations have established links and provided support to universities. Also, many systems have been designed and developed to facilitate their operations, and improve their strategic planning capacity [1]. However, very little attention is given to individual colleges within universities, as evidenced by the lack of efficient

Manuscript received November 15, 2013; revised January 16, 2014.

M. M. Tan is with the Polytechnic University of the Philippines, Manila Philippines (e-mail: mjmtan@gmail.com).

A. Crisostomo, B. Villaflor, and J. Faller are the College of Computers and Information Science of the Polytechnic University of the Philippines, Philippines (e-mail: allan.crisostomo@pup.edu.ph, bill.villaflor@ymail.com ajcastelfaller@gmail.com) facilities for private and government entities to directly interface with the college coordinators and administrators, the lack of physical resources available for own use of the college, and the lack of information systems that assist the individual colleges in its operations and decisions.

College administrators face huge challenges in complying with policies and standards of their respective academic institution, in providing quality instructions to students, in developing their faculty members, in upgrading their program and curriculums, and in managing the college's own operations. These challenges warrant an effective and efficient system that assists college administrators in management and decision-making, such as a College Management Information System (CMIS).

Management Information Systems (MIS) are distinct from other information systems, in that they are used to analyze and facilitate strategic and operational activities by giving managers information that they need to make informed decisions. Management reports generated by the MIS include periodic scheduled reports which provide information via a specified format designed to provide managers with information on a regular basis, and exception reports which are produced only when exceptional conditions occur to reduce information overload instead of overwhelming decision makers with periodic detailed reports of business activity. MIS also provides features that allow demand reports and responses which are available when the managers require immediate access to vital information through the use of Web browsers, DBMS query languages, and report generators. Another feature is push reporting where information is pushed directly to the manager's respective networked workstation [2].

MIS can help business organizations gain competitive advantage in that, thru utilization of management tools and reports generated, they can do something better, faster, and cheaper compared to competitors in the market [3].

However in educational institutions, efforts are primarily concentrated to automatic processing of school-wide voluminous transactions to facilitate the operations, especially on student-related transactions. Very few venture into summarizing detailed transactional information to produce a more organized relevant reporting system that caters to middle-level managers, for their long-term plans and decisions. And these systems being adopted by schools are integrated modules that cater to the entire educational institution's business processes and therefore analytical data are very much centralized, not withstanding the fact that there are several colleges and departments within the educational institution, each being run by its respective supervisors and managers who make decisions and long-term plans for their respective units. For example, the School Information 
Management System (SIMS) is a suite of software covering all parts of a schools' administration, from behavior and achievement, planning curriculum and lesson structures, dinner money, educational learning plans, managing registration and admissions, and providing teachers, parents and pupils access to all this information over the internet through a Microsoft SharePoint based webpage [4]. It has expanded into an integrated Management Information System for managing school business processes and whole school improvement [5]. Like SIMS, most commercially available systems cater to the entire school operations. Further, most researches conducted to improve sustainability performance are on university level [6]. There is very limited study on meeting the needs of individual colleges within universities through college management information systems.

Unlike grade schools and secondary schools where resources are managed centrally and shared by the entire institution, universities have different colleges with own resources that are managed by designated college officials. Within each college and department are volumes of records, files and documents that contain important data that can be processed into a meaningful set of information that aids in the college management decision and planning process. Relevant information needed in assessing the quality of the programs being offered by the colleges are generally classified into different areas such as curriculum, faculty, physical facilities, research and extension works, among others. It is therefore important that documents and records related to these areas be managed efficiently from the creation, storage, update, communication and dissemination. Reports, files, and documents pertaining to these areas are normally kept in folders and stored in filers and cabinets. With this method, aside from difficulty in updating, maintaining and storing these files and documents, problems on data security and integrity are being encountered. Electronic documents residing in the computer's hard disk often get lost due to file corruption, hardware crash, and accidental file deletion and overwriting. Reporting is very time-consuming, inefficient and inaccurate [7].

The objective of this study is to design and develop a customizable college management information system that provides detailed and summarized information on colleges' critical areas being evaluated for funding and accreditations, that is accessible anywhere anytime as data is stored remotely and made available to users over the internet. This will help college administrators in making informed and timely decisions.

The study involves development of an operational prototype that has the following features: 1) customizable college website with content management system; 2) Secured page for website content administrators and system file administrators; 3) Information system portal with centralized management of college-wide (system) reference files (e.g. college programs, officials); 4) Facilities for archiving and retrieving previously archived contents; 5) Security features such as audit trails and password maintenance for system administrator; 6) User-defined and maintainable links and calls to corresponding software components or information management sub-systems for college faculty, curriculum, research, extension works and physical facilities; 7) Online storage and maintenance of .pdf files, documents and image files regarding the college faculty, researches, extension works, curriculum; 8) Collaborative environment thru discussion board and e-mail system; () Online record management of college master files for faculty, facilities and equipment, researches, extension works, curriculum; 10) Online transaction processing for reservation of college equipment and extension services request from outside entities; 11) Detailed, summary, exception, and statistical reports on the college faculty, curriculum, equipment, researches, and extension works presented in tables and graphs.

The study also involved testing and evaluation of the operational prototype by direct users and IT experts, and subjecting the results of the evaluation to statistical treatment for analysis, conclusion and recommendation for future works.

\section{THE DEVELOPED SYSTEM}

\section{A. System Architecture}

The cloud-based College Management Information System (CMIS) is composed of independent software components developed using different proprietary and non-proprietary web development tools. Application software and data are hosted by different cloud service providers that offer free Infrastructure as a Service (IaaS). This design is based on Service-oriented Architecture (SOA) as utilized by Ref. [8] and Ref. [9] in constructing school-wide systems. Using any modern browser like Google Chrome, Firefox, Opera, Safari, and IE10, the user can access the college website which can also serve as the College Information System Portal (CISP) that can launch the different sub-systems for faculty, research, extension, curriculum, and physical facilities. The website content administrator can add, edit, delete, and deactivate links to the different information systems of the college. In the CMIS, the following information systems have been defined and can be launched by the CISP: Faculty Information Management System (FIMS), Research Information Management System (RIMS), Extension Information Management System (EIMS), Curriculum Information Management System (CIMS), Physical Facilities Information Management System (PFIMS). Thru the links in the main page, authorized users can access the different college information system web pages and respective databases being hosted by different cloud service providers. The system architecture of CMIS is designed as described in Fig. 1.

\section{B. Software}

The software was designed such that anybody with internet access using modern browsers can visit the website of the college to view general information such as its mission, vision and objectives, college officials, contact details and history of the college, important announcements, recent and past events or activities of the college, and significant captured moments in the picture gallery. 


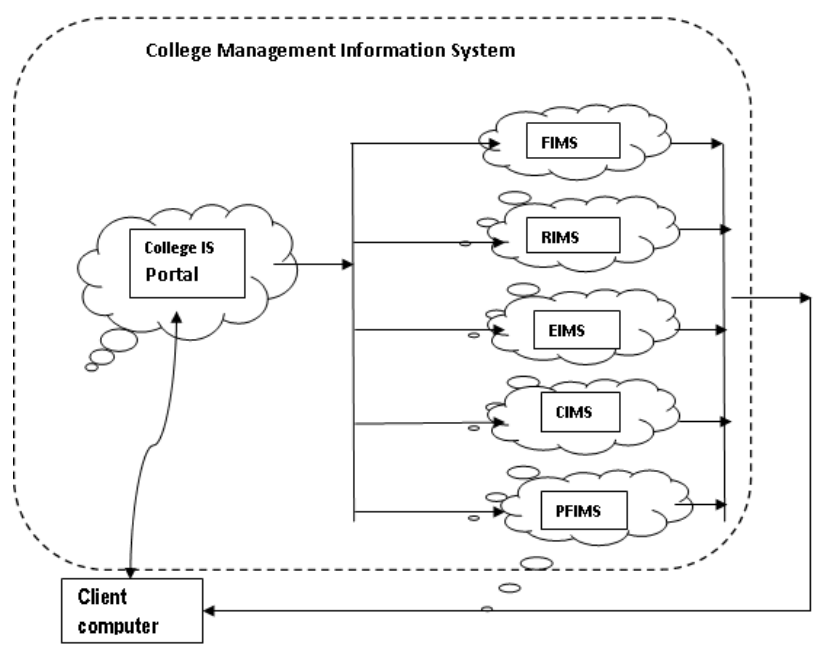

Fig. 1. CMIS system architecture.

Authorized content and system administrators can edit and maintain all these static information thru a secured page. Archived contents may also be retrieved by authorized content administrator.

The main page provides links to different information systems of the college. These links or corresponding calls to the different software components are editable and maintainable by authorized content administrator. Fig. 2 shows the structure and features of the College Information System Portal (CISP).

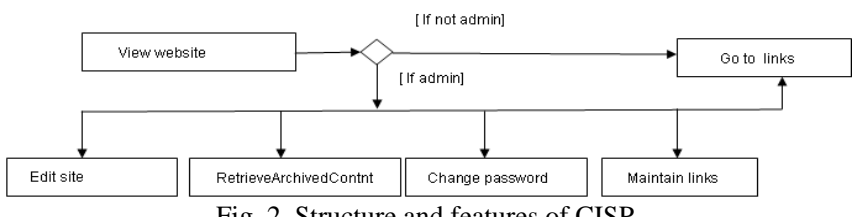

Fig. 2. Structure and features of CISP.

The link to the FIMS will launch the corresponding FIMS site. Fig. 3 shows the structure and features of the Faculty Information Management System (FIMS).

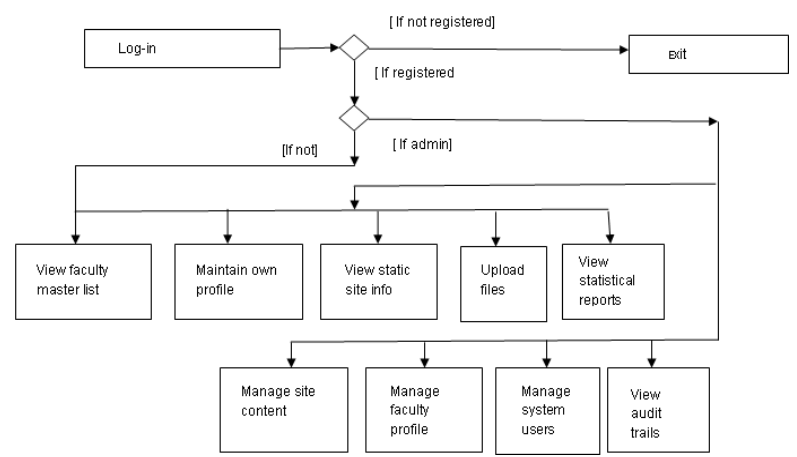

Fig. 3. Structure and Features of FIMS.

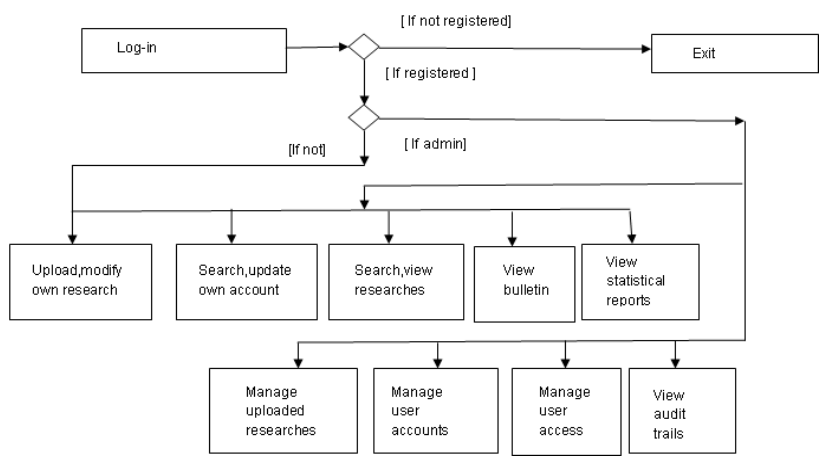

Fig. 4. Structure and features of RIMS.
The link to the RIMS will launch the corresponding RIMS site. Fig. 4 shows the structure and features of the Research Information Management System (RIMS).

The link to the EIMS will launch the corresponding EIMS site. Fig. 5 shows the structure and features of the Extension Information Management System (EIMS).

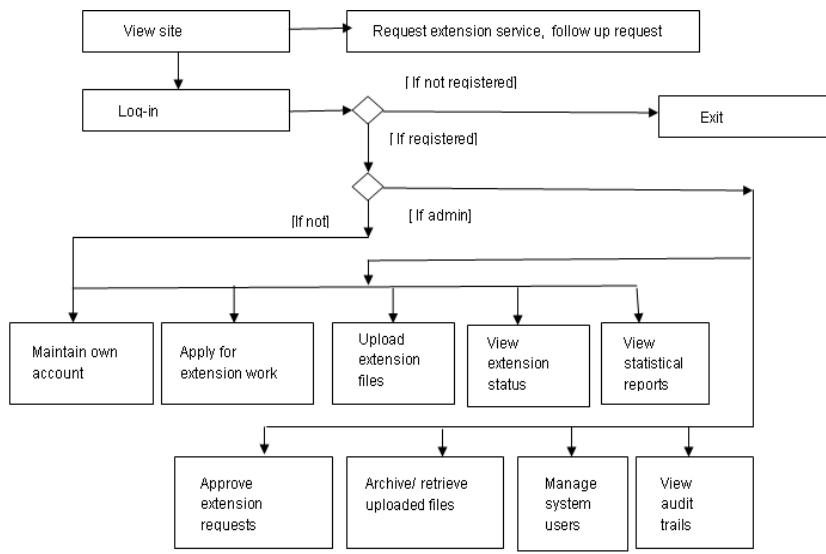

Fig. 5. Structure and features of EIMS

The link to the CIMS will launch the corresponding CIMS site. Fig. 6 shows the structure and features of the Curriculum Information Management System (CIMS).

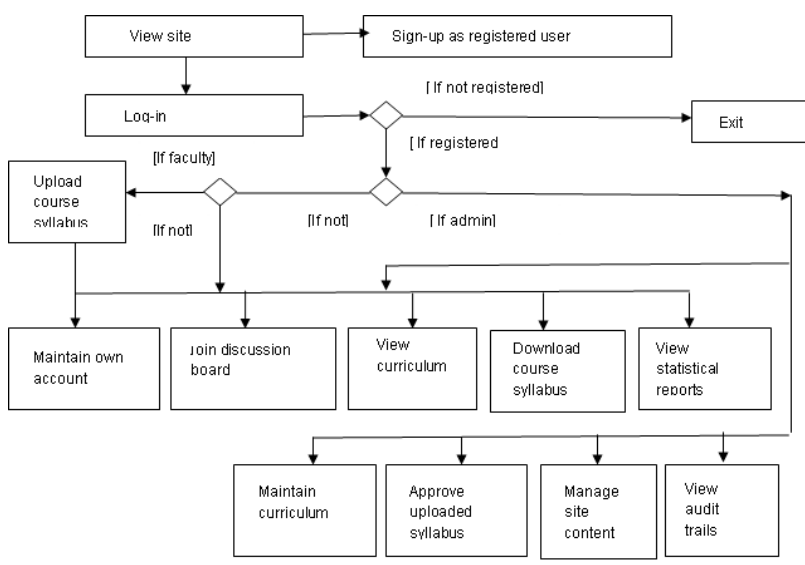

Fig. 6. Structure and features of CIMS.

The link to the PFIMS will launch the corresponding PFIMS site. Fig. 7 shows the structure and features of the Physical Facilities Information Management System (PFIMS).

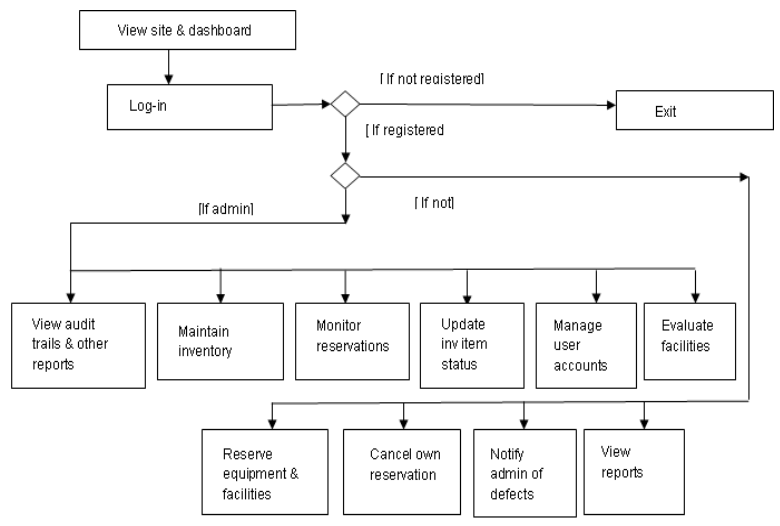

Fig. 7. Structure and features of PFIMS.

\section{Research Design}

Object-oriented method was used in the design and 
development of the computerized system following an incremental development process. Functional requirements were gathered and modeled using Use Case Diagrams and Detailed Use Case Reports. UML diagrams such as class diagrams and sequence diagrams were used to model the high-level and detailed design of the software. Structural and basic requirements were designed and developed first into an operational prototype which is released as the first version/increment subject to evaluation, revisions and enhancements. Other requirements and feedbacks on the first version will then be incorporated into future versions or next increments.

For CISP, .Net Framework and C\# Express2010 were used for development and hosted in host22.com. For FIMS, PHP is used in programming, HTML5 in scripting, PHPMyAdmin is the database management system, and Codeigniter MVC is the framework used. For RIMS, Adobe Dreamweaver is used in development and is hosted in Xampp utilizing PHP scripting, MySQL database and PHPMyAdmin database management tool. For PFIMS, CodeIgniter MVC Framework and PHP are used in development. For EIMS, PHP is used as web programming language together with MySQL front-end and DBMS. PHP and MySQL are commonly used tools for web based application and data maintenance, and were also used in Ref. [10] in the design and implementation of an academic search web application for various users in a university environment.

The operational prototype was presented and tested to the College of Computers and Information Science (CCIS) of the Polytechnic University of the Philippines (PUP). Direct users of the system such as the college's administrators, faculty members and students tested the system using the college's live data. It was also presented to a group of IT experts who have been practicing for at least five (5) years. To evaluate the system, a questionnaire-checklist was designed to rate it in terms of functionality, user-friendliness, usability, security, performance and robustness [11].

Results on the assessment by evaluators were tabulated and the weighted mean was computed. Likert Scale was used to rate each variable tested.

\section{RESUlTS AND DISCUSSION}

The following Likert Scale presented in Table I was used to verbally interpret the computed values.

TABLE I: LIKERT SCALE INDEX OF INTERPRETATION
\begin{tabular}{|c|c|c|c|}
\hline Interpretation & Code & Range & Scale \\
\hline Excellent & E & $1.00-1.49$ & 1 \\
\hline Very Satisfactory & VS & $1.50-2.49$ & 2 \\
\hline Good & G & $2.50-3.49$ & 3 \\
\hline Satisfactory & S & $3.50-4.49$ & 4 \\
\hline Unsatisfactory & U & $4.50-5.00$ & 5 \\
\hline
\end{tabular}

The CMIS was evaluated by sixteen (16) direct users of the system and eight (8) IT experts. After results were gathered and tabulated, Table II illustrates the summary of results for the assessment of the CMIS in terms of functionality, user-friendliness, usability, performance, security, and robustness.

TABLE II: SUMMARY OF RESULTS OF ASSESSMENT ON CMIS

\begin{tabular}{|l|c|c|c|c|c|c|c|}
\hline Variables Tested & $\mathrm{E}$ & $\mathrm{VS}$ & $\mathrm{G}$ & $\mathrm{S}$ & $\mathrm{U}$ & Weighted Mean & Verbal Interpretation \\
\hline Functionality & .26 & 1.0 & .56 & .29 & 0 & 2.11 & Very Satisfactory \\
\hline User-friendliness & .38 & .70 & .60 & .30 & .04 & 2.02 & Very Satisfactory \\
\hline Usability & .33 & .67 & .54 & .22 & .49 & 2.25 & Very Satisfactory \\
\hline Performance & .24 & 1.06 & .50 & .22 & .07 & 2.08 & Very Satisfactory \\
\hline Security & .33 & .83 & .53 & .29 & 0 & 1.99 & Very Satisfactory \\
\hline Robustness & .10 & .67 & 1.62 & .11 & 0 & 2.50 & Good \\
\hline
\end{tabular}

\section{CONCLUSION}

From the evaluation of respondents on the CMIS, the researchers arrived to the following conclusions:

1) The CMIS is rated by evaluators 'very satisfactory' in terms of functionality, user-friendliness; usability, performance, security; while it is rated 'good' only in terms of robustness. This implies that the evaluators perceive that software robustness can still be improved and therefore it is recommended that the operational prototype be revised to incorporate more error trapping facilities and proper messaging that guides the user's actions in case of an error; and further testing be conducted to check its error recoverability features during unexpected power failure or database server failure. Another factor that could affect the evaluation in terms of robustness is the free hosting services that may not be stable at the time of evaluation. It is therefore recommended that a standard platform that is most cost-effective be evaluated and adopted to host all the sub-systems.

2) This study shows the importance of providing management information system for colleges operating within a university so that college administrators can have more informed and timely decisions and plans. As CMIS was customizable and was rated very satisfactory in terms of functionality, user-friendliness, usability, and performance, it is implied that other colleges may adopt this system for more efficient information management and more effective management decisions. As CMIS was rated very satisfactory in terms of security, it is implied that relevant data stored in the cloud is deemed secured and this environment is considered acceptable.

3) This study shows the effectiveness of modularizing 
systems according to function or service, developing them individually and independently of each other, utilizing different tools and platforms for the development and implementation of these different systems; following the service-oriented architecture. Moreover, it shows that modularization of system into different software components works best when design is customizable and all parameters can be defined and stored in database, by authorized system users.

4) For more uniformity, the following revisions have to be applied to the software for its next release/increment:

- Revise the programs such that all college-wide values set in the portal's reference files (e.g. college officials, faculty members, programs, college name, logo, background, color) can be accessed and adopted by all the linked or called information systems

- Revise the programs to make each independent system "talk" to each other by passing value parameters to avoid data redundancy and maintain data consistency and integrity

5) The following actions are further recommended:

- Increase the usability of the software by including more statistical, comparative, and exception reports for management use

- Revise the software such that it can be accessed by mobile computing devices like tablet PCs and smart phones

- Integrate document imaging system feature to directly capture images of documents into the system

- Include more information management sub-systems such as student support, administration, program evaluation, and other areas of the college.

\section{ACKNOWLEDGMENT}

The authors would like to acknowledge B.V. Comendador for guidelines regarding research document; and Jeffrey Saballo, Richard Domingo, Paul Artigo, Deo Guillermo, Kim Alcantara, Jerome Layron, John Lazarte for the programming assistance.

\section{REFERENCES}

[1] R. B. Guin, S. Chakrabarti, C. Tarafdar, and S. Mandal, "A smart architectural concept for the making of a university education system using cloud computing paradigm," in Proc. 2011 World Congress on Information and Communication Technologies, Mumbai, 2011, pp. 48-52.

[2] R. M. Leod, Management Information Systems, Third Ed., Science Research Associates, 1986, pp. 17-19.

[3] L. Long, Management Information System, Prentice Hall, 1989, pp. 116-117.

[4] SIMS Product Brochures.

[5] Pupils, parents and LEAs get easy online access to vital school records through Microsoft's Learning Gateway. (January 11, 2006). (Press release). Microsoft. [Online]. Available: http://www.capitaes.co.uk/Home/Downloads/MS-CES-LG.pdf

[6] D. B. Heras, D. Otero, and F. Arguello, "An eco-feedback system for improving the sustainability performanceof universities," in Proc. 2011 IEEE International Conference on Virtual Environments Human-Computer Interfaces and Measurement Systems, Ottawa, ON, 2011, pp. 1-6.

[7] Y. Wang, B. Y. Sun, and F. Cheng, "Electronic document-based process model for image archives in universities," in Proc. 2011 International Conference on Information Technology, Computer Engineering, and Management Sciences, Nanjing, Jiangsu, pp. 57-60.

[8] X. X. Xin, R. M. Wu, and H. H. Li, "A faremework model of the e-campus management system based on SOA," in Proc. 2009 International Conference on Computational Intelligence and Software Engineering, Wuhan, 2009, pp. 1-3.

[9] H. M. Wei and L. J. He, "Constructing the comprehensive academic affairs management system based on SOA," in Proc. $20091^{s}$ International Conference on Information Science and Engineering, Nanjing, Jiangsu, pp. 3261-3264.

[10] S. Jeyalatha, B. Vijayakumar, and G. S. Wadhwa, "Design and implementation of web based application for relational data maintenance in an university environment," in Proc. 2011 International Conference and Workshop on Current Trends in Information Technology, Dubai, pp. 105-112.

[11] K. Saleh, Sofware Engineering, Phil. Ed. Cengage Learning Asia Pte Ltd, 2010, ch. 3, pp. 72-77.

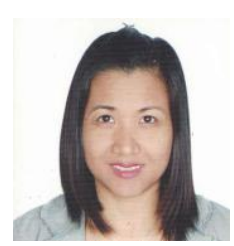

Mary Jane M. Tan is a member of the Association of Computing Machineries and of the Science and Engineering Institute. She earned her master's degree in information technology from the Polytechnic University of the Philippines Graduate School in 2005 She worked as a systems analyst in Applied Ideas, Incorporated in the Philippines from 1992 to 1997. In 1997, she started teaching at the Polytechnic University of the Philippine's College of Computer Management and Information Technology. Ms. Tan is currently a full-time instructor at the Polytechnic University of the Philippines's College of Computers and Information Science specializing in Systems Analysis and Design and Software Engineering.

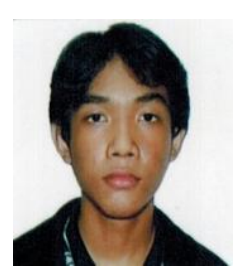

Allan V. Crisostomo is a senior student of computer science at the Polytechnic University of the Philippine's College of Computers and Information Science.

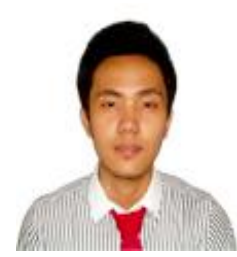

Bill Villaflor is a senior student of computer science at the Polytechnic University of the Philippine's College of Computers and Information Science.

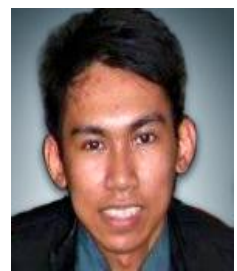

James C. Faller is a senior student of computer science at the Polytechnic University of the Philippine's College of Computers and Information Science. 